\title{
KOORDINASI EKSTERNAL DINAS LALU LINTAS DAN ANGKUTAN JALAN TENTANG IMPLEMENTASI SISTEM SATU ARAH DIKOTA BOGOR
}

\section{EXTERNAL COORDINATION OF TRAFFIC AND ROAD TRANSPORTATION AGENCY ABOUT IMPLEMENTATION OF ONE WAY DIRECTION SYSTEM IN BOGOR CITY}

\section{Khoerudin ${ }^{1 *}$, Deny Hernawan², Irma Purnamasari ${ }^{3}$.}

1Jurusan Ilmu Administrasi Negara Fakultas Ilmu Sosial dan Ilmu Politik Universitas Djuanda, Jl Tol Ciawi Ni 1, Kotak Pos 35 Bogor 16770.

2Jurusan Ilmu Administrasi Negara Fakultas Ilmu Sosial dan Ilmu Politik Universitas Djuanda, Jl Tol Ciawi Ni 1, Kotak Pos 35 Bogor 16770.

${ }^{3}$ Jurusan Ilmu Administrasi Negara Fakultas Ilmu Sosial dan Ilmu Politik Universitas Djuanda, Jl Tol Ciawi Ni 1, Kotak Pos 35 Bogor 16770.

*Korespondensi: Khoerudin. HP: 085715980916; E-mail: khoerudin@unida.ac.id

(Diterima Oleh Dewan Redaksi: 01-08-2017)

(Dipublikasikan Oleh Dewan Redaksi: 01-10-2017)

\begin{abstract}
In implementing the policy of One Way Direction System in Bogor City, it is necessary to have well-coordination between Traffic and Road Transportation Agency (DLLAJ) of Bogor City with related Institutions/Agencies. If one of the agencies do not perform their duty well, then their goal to overcome the congestion will run ineffectively.

The purpose of this study is to know the direction of coordination between traffic and road transportation Bogor City with other agencies in applying a one-way direction system. The theory used in this research is by using the coordination theory of Handyaningrat which states that to produce a coordination can be measured through five variables as follow: (1) Communication, (2) Awareness of the Importance of Coordination, (3) Participant Competencies, (4) Agreements, Commitments, and Coordination Incentives, and (5) Continuity of Planning.

The method used is descriptive analysis using Qualitative approach. The data analysis technique used is to use the calculation of Weighted Mean Score (WMS). Technical data used are literature study, field study, interview and questionnaire. Unit of analysis of this study consist of 11 respondents. While the sampling technique used is saturated sample technique.

In general, the results of external coordination conducted by Traffic and Road Transportation Agency (DLLAJ) of Bogor City in implementing one-way direction system is obtained an average score of 3.81 which according to structuring criteria are in good category. While the existing variety in moderate criteria is an indicator of whether or not there are casualties for offenders exist with average score of 3.18. Meanwhile the indicator that produces a very good score is on the indicator of whether or not the executor of the activity with a score of 4.18. In sum, the average score of all indicators is in good criteria.
\end{abstract}

Keywords: Coordination, Implementation, Policy. 


\begin{abstract}
ABSTRAK
Dalam mengimplementasikan kebijakan Sistem Satu Arah di Kota Bogor diperlukan adanya koordinasi antara Dinas Lalu Lintas dan Angkutan Jalan (DLLAJ) Kota dengan Instansi/Dinas terkait harus baik. Jika salah satu instansi tidak melaksanakan tugasnya dengan baik, maka tujuan mereka untuk mengatasi kemacetan akan berjalan secara tidak efektif.

Tujuan penelitian ini adalah mengetahui koordinasi eksternal antara Dinas Lalu Lintas dan Angkutan Jalan Kota Bogor dengan dinas lain dalam mengimplementasikan sistem satu arah. Teori dalam penelitian ini yaitu menggunakan teori koordinasi dari Handyaningrat yang menyatakan bahwa untuk mengukur keberhasilan suatu koordinasi dapat di ukur melalui lima variabel diantaranya : Komunikasi, Kesadaran Pentingnya Koordinasi, Kompetensi Partisipan, Kesepakatan, Komitmen dan Insentif Koordinasi, Kontinuitas Perencanaan.

Metode penelitian ini adalah metode deskriptif analisis dengan pendekatan Kualitatif. Sedangkan teknik analisis data yaitu dengan menggunakan perhitungan Weight Mean Score (WMS). Pengumpulan data menggunakan teknik studi kepustakaan, studi lapangan, wawancara dan angket. Unit analisis penelitian ini berjumlah 11 responden dengan menggunakan teknik sampling jenuh.

Secara umum hasil penelitian koordinasi eksternal dinas lalu lintas dan angkutan jalan tentang implementasi sistem satu arah Kota Bogor diperoleh skor rataan sebesar 3,81 yang menurut penafsiran kriteria berada pada kategori baik. Adapun ragam nilai yang memperoleh nilai sedang adalah pada indikator keberadaan sanksi untuk pelanggar yaitu 3.18, sedangkan indikator yang memperoleh skor sangat baik ialah pada indikator keberadaan pelaksana kegiatan dengan skor 4.18. Secara keseluruhan ratarata nilai yang diperoleh yaitu baik.
\end{abstract}

Kata Kunci: Koordinasi, Implementasi, Kebijakan.

Khoerudin, 2017. Koordinasi Eksternal Dinas Lalu Lintas dan Angkutan Jalan tentang Implementasi Sistem Satu Arah Kota Bogor. Jurnal Governansi. 


\section{PENDAHULUAN}

Seiring pertumbuhan jumlah penduduk di dunia, maka kota besarpun bertambah jumlah penduduknya nya sehingga menjadikan mobilitas manusia dari dan menuju wilayah perkotaan semakin meningkat. Kondisi tersebut disebabkan oleh wilayah perkotaan yang merupakan pusat kegiatan ekonomi sehingga menimbulkan daya tarik ekonomi bagi masyarakat. Daya tarik tersebut merupakan magnet bagi masyarakat baik bagi masyaarakat di wilayah kota itu sendiri dan masyarakat yang tinggal disekitar wilayah perkotaan. Hal ini menciptakan fenomena jam sibuk di jalanan perkotaan yang mengakibatkan kemacetan yang terjadi pada pagi hari ketika aktifitas perekonomian dimulai, dan sore hingga malam hari saat masyarakat kembali ke rumah masing-masing.

Mobilitas masyarakat yang tinggi tersebut mengharuskan pemerintah menyediakan sarana yang memadai yang mampu mengakomodir jumlah perjalanan di wilayah perkotaan. Langkah yang paling mendasar untuk memecahkan masalah mobilitas masyarakat diperkotaan tersebut adalah dengan membangun sistem transportasi yang menjangkau seluruh titik-titik penting (point of interest) di perkotaan. Langkah ini membutuhkan komitmen dari pemerintah khusunya pemerintah kota untuk membangun sebuah sistem transportasi yang efisien dan efektif, yaitu sistem transportasi yang aman, murah, tepat waktu dan mampu menjangkau seluruh lapisan masyarakat.

Keadaan demikian tentu saja berdampak pada menurunnya kinerja lalu lintas dan tingkat pelayanan dari ruas jalan maupun persimpangan yang ada di Kota Bogor. Tidak seimbangnya pertambahan jumlah kendaraan, masih rendahnya kualitas pelayanan angkutan umum kota.

Sebagai langkah awal, Pemerintah Kota Bogor menerapakan sistem satu arah (SSA) arus lalu lintas di jalan utama seputar Istana Negara Bogor dan sekeliling Kebun
Raya Bogor setelah disosialisasikan oleh Pemerintah Kota Bogor.

Kota Bogor beralasan kenapa Sistem Satu arah ini harus di terapkan diantaranya lain sebagai berikut: Memikul beban 1,2 juta perjalanan orang setiap hari, Menjadi perlintasan 600.000 commuter yang $50 \%$ dari luar kota, Dilintasi 13 trayek angkot, untuk aktifitas masyarakat di sekolah, kantor, pasar dan pusat perbelanjaan, banyaknya persimpangan jalan.

Ini terbukti setelah diterapkannya sistem satu arah pada ruas jalan di Kebun Raya dan Istana Kepresidenan, pada dasarnya mampu membuat arus lalu lintas lokasi jalan tersebut menjadi lancar dikeempat ruas jalan lingkar Kebun Raya Bogor dan ruas jalan pendukung, mengurangi penyebab kemacetan dan kecelakaan lalulintas, meningkatkan kecepatan lalu lintas, juga menghemat waktu tempuh di perjalanan.

Didalam undang-undang nomor 22

tahun 2009 tentang lalu lintas dan angkutan jalan disebutkan bahwa penyelenggaraan lalu lintas dan angkutan jalan bersifat lintas sektor sehingga dalam pelaksanaanya harus terkoordinasi oleh Pembina beserta para pemangku kepentingan (stakeholders). untuk mengatasi masalah yang sangat kompleks tersebut, undang-undang ini mengamanatkan dibentuknya forum lalu lintas dan angkutan jalan yang memiliki fungsi sebagai wahana untuk menyinergiskan tugas pokok dan fungsi setiap instansi penyelenggara lalu lintas dan angkutan jalan dalam rangka menganalisa permasalahan, sebagai jembatan, menemukan solusi, serta meningkatkan kualitas pelayanan, dan bukan sebagai aparat penegak hukum.

Berkaitan dengan wewenang dan tugas Dinas Lalu Lintas dan Angkutan Jalan (DLLAJ) bidang lalu lintas dan angkutan jalan, dalam melaksanakan tugas dan fungsinya, DLLAJ agar selalu berkoordinasi dengan pihak lain agar tidak terjadi tumpang tindih kewenangan serta adanya kepastian hukum sebagaimana telah diatur 
dalam peraturan perundang - undangan. Adapun tugas DLLAJ yaitu melaksanakan koordinasi lintas instansi penyelenggara yang membutuhkan keterpaduan dalam hal merencanakan dan menyelesaikan masalah lalu lintas dan angkutan jalan.

Bidang Lalu Lintas di Dinas Lalu Lintas dan Angkutan Jalan (DLLAJ) sebagai bidang yang melaksanakan penerapan Sistem Satu Arah dibawah tanggung jawab Kepala Dinas Lalu Lintas dan Angkutan Jalan (DLLAJ), dalam pelaksanaannya telah berkoordinasi dengan beberapa Satuan Kerja Perangkat Daerah (SKPD) dan Instansi demi terwujudnya penerapan sistem satu arah dengan baik dan lancer, diantaranya Kepala Satuan Lalu Lintas Polres Bogor Kota sebagai aparat yang menegakkan hukum dijalan, Kepala Dinas Bina Marga dan Sumber Daya Air Kota Bogor sebagai dinas yang bertugas menjaga dan memfasilitasi jalan, dan Kepala Satuan Polisi Pamong Praja Kota Bogor sebagai dinas yang bertugas penegak peraturan walikota, serta Dewan Pengurus Cabang Organisasi Pengusaha Angkutan Darat Kota Bogor sebagai salah satu yang terkena dampak kebijakan.

Dalam mengimplementasikan kebijakan Sistem Satu Arah di Kota Bogor diperlukan adanya koordinasi antara Dinas Lalu Lintas dan Angkutan Jalan (DLLAJ) Kota dengan Instansi/Dinas terkait harus berkoordinasi dengan baik jika salah satu instansi tidak berkoordinasi dengan baik, maka tujuan mereka untuk mengatasi kemacetan akan berjalan secara tidak efektif.

Dari koordinasi tersebut dalam prakteknya ada hambatan-hambatan yang terjadi diantaranya adanya keegoisan hubungan antar instansi, rapat koordinasi bersifat insidentil, disharmoni hubungan antar SKPD, padahal tujuan utamanya sama yaitu melaksakan kewajibannya sebagai aparatur sipil negara harus mematuhi segala peraturan yang ada. Disini pentingnya suatu kesadaran antar instansi agar koordinasi bisa berjalan dengan lancar.

\section{MATERI DAN METODE}

Teori dalam penelitian ini menggunakan teori dari Handayaningrat (1989:80), dari sisi normatif, koordinasi dapat diartikan sebagai wewenang untuk menggerakkan, menserasikan, menyelaraskan, dan menyeimbangkan kegiatan-kegiatan yang berbeda-beda atau spesifik agar terarah pada tujuan tertentu. Sedangkan secara fungsional, koordinasi dijalankan untuk mengurangi dampak negatif spesialisasi dan mengefektifkan pembagian kerja (Ndraha, 2003:290. Secara umum, handayaningrat menggambarkan kriteria - kriteria koordinasi sebagai berikut: Komunikasi, Kesadaran Pentingnya Koordinasi, Kompetensi Partisipan, Kesepakatan, Komitmen, dan Insentif Koordinasi, Kontinuitas Perencanaan.

Metode yang digunakan dalam penelitian ini adalah metode Deskriptif Analisis. Menurut sugiyono (2012:11) deskriptif adalah penelitian yang dilakukan untuk mengetahui nilai variabel mandiri, baik satu variabel atau lebih tanpa membuat perbandingan, atau menghubungkan antara variabel satu dengan variabel yang lain. Penelitian ini menggunakan pendekatan kuantitatif.

\section{Unit Analisis}

Unit analisis penelitian ini adalah individu dan kelompok. Unit analisis individu adalah seluruh pegawai Bidang Lalu Lintas di Dinas Lalu Lintas dan Angkutan Jalan (DLLAJ) Kota Bogor yang berjumlah 11 orang pegawai.

Dari jumlah pegawai di atas peneliti menarik sampel dengan menggungunakan Sampling Jenuh yaitu teknik sample dimana semua anggota populasi digunakan sebagai sample. Hal ini sering dilakukan bila jumlah populasi relatif kecil, kurang dari 30 orang, atau dengan maksud penelitian yang ingin membuat generalisasi dengan kesalahan yang sangat kecil. Istilah lain sample jenuh adalah sensus, dimana semua anggota populasi dijadikan sample. (Sugiyono 2012: 96). 


\section{Teknik Pengumpulan Data}

Untuk memperoleh data yang diperlukan, maka penulis menggunakan beberapa teknik pengumpulan data sebagai berikut:

1. Teknik Studi Lapangan

Teknik ini untuk memperoleh data primer adalah dengan melakukan pengamatan lagsung di tempat yang dijadikan objek penelitian yaitu di Dinas Lalu Lintas dan Angkutan Jalan Kota Bogor.

2. Kuesioner (angket)

Merupakan metode pengumpulan data dengan menggunakan sejumlah pertanyaan bersifat tertulis, digunakan untuk memperoleh informasi dari responden dalam arti laporan tentang pribadinya, atau hal-hal yang ia ketahui (Arikunto, 2006: 151).

3. Wawancara

Teknik

ini dilakukan mengumpulkan data dengan melakukan Tanya jawab secara lisan kepada responden tentang pelaksanaan Implementasi Sistem Satu Arah di Kota Bogor.

4. Studi kepustakaan,

Teknik ini digunakan untuk memperoleh data sekunder. Studi kepustakaan yang dilakukan dengan cara membaca, mempelajari, mengutip, dan merangkum data yang berkaitan yang berkaitan dengan Koordinasi Dinas Lalu Lintas dan Angkutan Jalan Kota Bogor dalam mengimplementasikan Sistem Satu Arah di Kota Bogor.

\section{Teknis Analisis Data}

Teknik analisa data dalam penelitian ini menggunakan perhitungan Weight means Score (WMS) Menurut Bakri siregar (1981:20) data yang diperoleh dari lapangan lalu diolah berdasarkan jawaban responden $\mathrm{M}=\frac{\sum(\mathrm{fx})}{\mathrm{n}}$ gket yang
Keterangan :

$\mathrm{M}=$ Perolehan angka kriteria penafsiran

$\mathrm{f}=$ Frekuensi jawaban

$\mathrm{x}=$ Pembobotan (skala nilai)

$\sum=$ Penjumlahan

$\mathrm{n}=$ jumlah seluruh jawaban responden

Dari ketentuan diatas, maka tingkat kategori jawaban yang diperoleh ditentukan dengan kriteria penafsiran sebagai berikut:

Tabel Kriteria Penafsiran

\begin{aligned} & \hline \multicolumn{1}{c}{ Skor } \multicolumn{1}{c}{ Kriteria } \\ & \hline $4,21-5,00$ Sangat Baik \\ & $3,41-4,20$ Baik \\ & $2,61-3,40$ Sedang \\ & $1,81-2,60$ Buruk \\ & $1,00-1,80$ Sangat Buruk \\ & \hline\end{aligned}

\section{HASIL DAN PEMBAHASAN}

Visi dan Misi DLLAJ Kota Bogor

Penertiban transportasi telah menjadi salah satu prioritas pembanguan di Kota Bogor. Sistem transportasi yang ada dan dikembangkan oleh pemeritah harus mampu menjawab masalah peningkatan mobilitas penduduk, baik yang berasal dari dalam kota maupun dari luar kota sebagai dampak Kota Bogor menjadi bagian kawasan aglomerasi perkotaan Jabodetabek. Dalam pelaksanaanya Pemerintah Kota Bogor mengutamakan prinsip pengembangan transportasi perkotaan yang berkelanjutan (sustainable urban transport), yaitu membalik arah kecenderungan orang yang pada awalnya menggunakan kendaraan pribadi menjadi pengguna angkutan umum, adapun konsekueni dari munculnya kebijakan tersebut yaitu harus mengembangkan angkutan umum massal, pejalan kaki dan pesepeda yang terintegrasi. Berangkat dari hal tersebut, Arah Kebijakan Pembangunan atau Rencana Strategis (RENSTRA) Dinas Lalu Lintas dan Angkutan Jalan Kota Bogor menetapkan Visi "Terwujudnya sistem transportasi Kota Bogor yang berkelanjutan, berkualitas dan 
berwawasan lingkungan", dengan maksud :

1. Sistem Transportasi: merupak satu kesatuan komponen terdiri dari prasarana (jalan, terminal dan stasiun KA), sarana dan sistem pengoprasian untuk mendukung kelancaran mobilitas antar tata guna lahan dalam memenuhi kebutuhan kehidupan ekonomi.

2. Berkelanjutan: Transportasi berkelanjutan (sustainable transportation) merupakan konsep yang mengaitkan antar tiga parameter yang saling berhubungan, secara komperhensif dan saling ketergantungan, yaitu lingkungan, sosial masyarakat dan ekonomi.

Berkelanjutan dalam penyelenggaraan transportasi, dengan ide dan prinsip;
a. Access (jangkauan)
b. Equity (keberadilan)
c. Pencegahan polusi
d. Kesehatan dan keselamatan.
e. Partisipasi masyarakat dan transparansi.
f. Perencanaan yang terintegrasi.
g. Manfaat ekonomi dan biaya yang rendah.

3. Pelayanan

Berkualitas: Kesepakata

Penyelengaraan transportasi yang Komitmen, aman (dari resiko kriminalitas), dan Insentif selamat (dari resiko kecelakaan), nyaman (tertib teratur dan rasa nyaman) dan handal (efisien/ cepat, murah; aksesibel/ mudah dijangkau dan dapat dijangkau oleh seluruh lapisan masyarakat; adanya integrasi antar moda/ fasilitas, terjadwal dengan system ticketing bagi penggunanya.

4. Berwawasan Lingkungan: Kebijakan strategis penyelenggaraan berdasarkan tujuan untuk mengurangi Gas Rumah Kaca (GRK).

Dalam pelaksanaan Koordinasi antara

Kompetensi Partisipasi Koordinasi ,

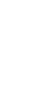


Dari tabel diatas menunjukan rekapitulasi jawaban dari responden terhadap Koordinasi Eksternal Dinas Lalu Lintas dan Angkutan Jalan tentang Impementasi Sistem Satu Arah Di Kota Bogor diperoleh skor sebesar 3,81 yang menurut penafsiran kriteria berada pada kategori baik.

Ada beberapa kesimpulan dari rekapitulasi Koordinasi Eksternal Dinas Lalu Lintas dan Angkutan Jalan tentang Impementasi Sistem Satu Arah Di Kota Bogor dengan mengacu pada model William Dunn, Secara umum kebijakan sistem satu arah termasuk dalam kategori baik (nilai rataan keseluruh indikator sebesar 3,81 dalam skala 5).

Apabila dirinci menurut dimensi dalam koordinasi maka indikator pelaksana kegiatan merupakan dimensi dengan nilai rata-rata paling besar yaitu 4,36 relatif terhadap dimensi lainnya. Sementara itu indikator kesepakatan secara relative merupakan dimensi dengan nilai yang rendah dengan nilai 3,18.

Didalam pelaksanaan koordinasi mengimplementasikan sistem satu arah di Kota Bogor ini, ada beberapa kendala ataupun hambatan yang dialami oleh dinas yang terlibat, diantaranya:

a. Kurang efektifitasnya wakil SKPD didalam rapat yang berganti-ganti.

Dari hasil wawancara dengan Seksi Trantib dan Linmas Satuan Pamong Praja Kota Bogor mengatakan didalam rapatrapat tertentu sering terjadinya perdebatan antar dinas-dinas yang terlibat mengenai hak kebijakan sistem satu arah ini dikarenakan saling mementingkan keegoisan masing-masing akan tetapi saling melempar tanggung jawab. Yang menjadi dampak kurangnya koordinasi kebijakan ini yaitu tidak menemukan titik kesepakatan pada awal dimulainya forum. Akan tetapi dengan menggandeng beberapa pejabat pemerintah kota seperti walikota dan jajarannya yang terkait didalam masalah koordinasi kebijakan sistem satu arah ini, sehingga bisa mencapai hasil kesepakatan yang sesuai dengan rencana atau tujuan awal yang telah ditentukan dalam pelaksanaan koodinasi kebijakan sistem satu arah dikota bogor.

b. Infomasi yang tidak berkesinambungan Selain hambatan diatas adapula hambatan lain yang terjadi saat pelaksanaan koordinasi yaitu Adanya keputusan yang dibuat kurang sempurna, karena kurangnya bahan yang terhimpun dari berbagai unit yang disebabkan oleh berganti-gantinya wakil SPKD dalam kegiatan rapat.

c. Koordinasi yang bersifat insidental.

Berdasarkan

hasil

wawancara dengan beberapa pegawai menyatakan bahwa ketika terjadi permaslahan dilapangan biasanya Dinas melakukan koordinasi yang bersifat insidental untuk mengatasi masalah yang terjadi dilapangan.

\section{KESIMPULAN DAN IMPLIKASI}

Berdasarkan hasil penelitian yang telah diakukan ada beberapa kesimpulan penting terkait koordinasi eksternal Dinas Lalu Lintas dan Angkutan Jalan tengtang implementasi sistem satu arah di Kota Bogor adalah sebagai berikut:

1. Diketahui bahwa rata-rata rekapitulasi jawaban responden terhadap lima dimensi yang ada dalam Variabel koordinasi adalah 3.81dan menurut kriteria penilaian berdasarkan angka penafsiran maka Variabel Koordinasi berada pada kategori baik.

2. Secara umum diketahui bahwa ratarata jawaban responden terhadap dimensi Kesepakatan, Komitmen, dan Insentif Koordinasi merupakan dimensi dengan nilai rata-rata paling tinggi yaitu 4.11 dan menurut kriteria penilaian berdasarkan angka penafsiran maka Dimensi Kesepakatan, Komitmen, dan Insentif Koordinasi berada pada kategori Baik. 
3. Sedangkan dimensi dengan rata-rata nilai terendah adalah dimensi komunikasi dan dimensi kontinuitas perencanaan yaitu 3.72 dan 3.49 dan menurut kriteria penilaian berdasarkan angka penafsiran berada pada kategori Baik.

4. Hambatan dalam koordinasi tentang implementasi sistem satu arah di Kota Bogor yaitu Kurangnya koordinasi antar instansi sehingga terjadinya lempar tanggung jawab.

5. Dalam setiap kebijakan yang akan dilaksanakan harus adanya pembagian kerja yang jelas dan semua pekerjaan harus terbagi secara merata agar tidak saling lempar tangggung jawab.

6. Pupuklah semangat kerjasama dalam arti yang baik.

7. Siapkan fasilitas komunikasi yang memadai agar dalam berkoordinasi bisa berjalan dengan baik.

8. Ciptakan langkah-langkah koordinasi secara berkelanjutan agar dalam setiap kebijakan yang akan dibuat.

9. Forum Lalu Lintas Tidak hanya melibatkan unsur Muspida saja, tetapi bisa melibatkan unsur masyarakat juga.

\section{DAFTAR PUSTAKA}

Handayaningrat, Soewarno.1980.Pengantar Studi Ilmu Administrasi dan Manajemen. Jakarta: CV. Haji Masagung.

Sugiyono. 2012. Metode Penelitian Administrasi dilengkapi dengan Metode $R$ dan $D$. Bandung: Penerbit Alfabeta.

William, N. Dunn. 2012, Pengantar Analisis Kebijakan Publik, Edisi Kedua, Gajah Mada University Press, Yogyakarta

\section{Sumber Dokumen:}

Profil \& Direktori Dinas Lalu Lintas dan Angkutan Jalan Kota Bogor.
Peraturan Daerah Kota Bogor No 3 Tahun 2013 Tentang Penyelenggaraan Lalu Lintas dan Angkutan Jalan 